\section{A Ten-Year Trend Analysis of Cancer-Related Search Queries in the Philippines}

JOSE MA. H. ZALDARRIAGA (D)

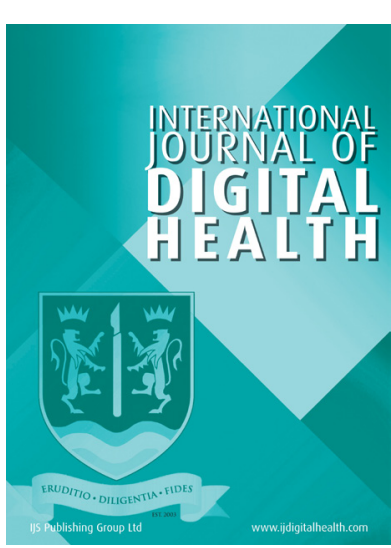

REVIEW ARTICLE
CORRESPONDING AUTHOR:

\section{Jose Ma. H. Zaldarriaga, MD MBA}

Ateneo School of Medicine and Public Health Don Eugenio Lopez, Sr. Medical Complex, Ortigas Avenue, Pasig City, Metro Manila, $\mathrm{PH}$

jose.zaldarriaga@obf.ateneo. edu

\section{KEYWORDS:}

cancer; oncology; Philippines; telemedicine; ehealth

\section{TO CITE THIS ARTICLE:}

Zaldarriaga JMaH. A Ten-Year Trend Analysis of CancerRelated Search Queries in the Philippines. International Journal of Digital Health. 2021; 1(1): 17, 1-5. DOI: https://doi. org/10.29337/ijdh. 41

Conclusion: This study revealed a significant increase in cancer-related search activity in the Philippines in recent years. 


\section{INTRODUCTION}

The internet has revolutionized the way patients access information about their health; physicians are no longer the sole providers of information about their diagnosis and treatment options [1, 2]. More than 12.5 million health-related computer searches are conducted on the internet each day [3]. Historically, cancer has been and still is one of the most popular health-related searches worldwide, accounting for 5-10\% [1, 3, 4]. Internet use, either directly or via friends or family, is widespread among patients across the full spectrum of cancer care, from early investigations to follow-up after treatment [4].

The internet has been posited to positively impact how cancer patients navigate their disease, particularly in terms of supplementing the health information they obtain from their healthcare providers, as well as in engaging and being part of online support groups [4-6]. However, the internet is likewise replete with misinformation, inconsistencies, and unregulated advice for which both patient and physician must be vigilant $[7,8]$. For this reason, there has been growing interest in analyzing the trends of internet search queries as a means of gauging population perceptions of and attitudes and behaviors towards health [9-12], specifically search queries in the Google search engine which is the world's largest as it accounts for over $70 \%$ of the web search industry $[11,12]$. The ultimate goal of this analysis is to inform public health and policy [13].

The Philippines, a developing country in Southeast Asia, has a population of more than 109 million people, making it the $8^{\text {th }}$ most populated country in Asia and the $13^{\text {th }}$ most populated in the world [14]. As of January $2020,67 \%$ of the total Philippine population have access to the internet [15]. Despite the prevalence of internet usage in the country, however, trends of search queries have rarely if at all been analyzed and thus utilized to inform patient and physician behavior and public policy. In particular, there is yet no published study analyzing cancer-related internet search trends in the Philippines. This is despite the fact that cancer ranks as the third leading cause of morbidity and mortality in the country, after communicable diseases and cardiovascular diseases $[16,17]$. It is this gap which this study seeks to fulfill.

\section{METHODS}

All search queries in Google are indexed and can be accessed using Google Trends ${ }^{\mathrm{T}}$, an unrestricted and open-access online tool. Analyzing the trends and patterns of a particular search query using Google Trends $^{\text {TM }}$ necessitates specifying a time period and geographical area/s for analysis. One subsequently specifies a search term/s. For every selected time point, Google Trends" then calculates what is called a "Search
Volume Index" (SVI) which specifies the proportion of search queries containing the inputted search term/s in comparison to the total number of searches performed during the specified time period and geographical area/s of study. The SVI ranges from 0 to 100; an SVI of 100 signifies the peak popularity of search queries containing the specified search term/s whereas an SVI of 0 indicates insufficient data for the search term/s.

For this study, the following cancer-related search terms were pre-selected- "cancer", "kanser" (official Filipino translation for "cancer"), "tumor", and "bukol" (official Filipino translation for "tumor"). Each was then inputted into Google Trends ${ }^{\mathrm{Tm}}$, with the following search parameters set: "Philippines" as geographical area, "Custom time range" set to December 31, 2009 to December 31, 2019 as the time period, "All categories" set as the search category, and "Web Search" set as the search modality. SVI values were then calculated in monthly intervals. Comma Separated Values (CSV) files were then downloaded into Microsoft Excel for each of these four search terms. The SVI data from the CSV files were arranged in arrays and transferred to IBM SPSS Statistics 21. A two-way repeated measures (RM) analysis of variance (ANOVA) was then performed to determine whether there exists a statistically significant difference between the specified cancer-related search terms across the time period of study. If a statistically significant difference was found, post hoc Dunnett's multiple comparisons test would then be performed to explore the trend of these differences, with 2009 set as the baseline.

\section{RESULTS}

Two-way RM ANOVA revealed a statistically significant difference between the cancer-related search terms across 2009 to 2019, $F(4.512,169.3)=140.9, p<$ 0.0001; hence, Dunnett's multiple comparisons test was subsequently performed. Statistically significant increases in SVI were noted for the search term "cancer" in 2016 ( $p=0.010), 2017$ ( $p=0.019), 2018$ ( $p=0.004)$, and 2019 ( $p=0.006)$. For the search term "kanser", statistically significant increases were noted for 2017 ( $p=0.023), 2018$ ( $p=0.044)$, and $2019(p=0.042)$. There was a statistically significant increase in the search term "tumor" for 2016 ( $p=0.026), 2017(p=0.022), 2018(p=0.004)$, and 2019 $(p=0.006)$. Finally, for the search term "bukol", $a$ statistically significant increase was noted in 2017 ( $p=$ $0.008), 2018$ ( $p=0.004)$, and $2019(p=0.006)$ (Table 1).

\section{DISCUSSION}

For all pre-specified cancer-related search terms, statistically significant increases in SVI were noted in 2016 up to 2019, pointing to a significant increase in 


\begin{tabular}{|c|c|c|c|c|}
\hline SEARCH TERM & YEAR & MEAN DIFFERENCE & 95\% CONFIDENCE INTERVAL OF DIFFERENCE & P-VALUE \\
\hline \multirow[t]{10}{*}{ Cancer } & 2009 vs 2010 & 7 & -5.651 to 19.65 & 0.149 \\
\hline & 2009 vs 2011 & -3.833 & -11.78 to 4.114 & 0.188 \\
\hline & 2009 vs 2012 & -5.583 & 12.04 to 0.8725 & 0.066 \\
\hline & 2009 vs 2013 & -6.333 & -15.71 to 3.040 & 0.104 \\
\hline & 2009 vs 2014 & -17.33 & -41.72 to 7.052 & 0.095 \\
\hline & 2009 vs 2015 & -32.92 & -73.20 to 7.363 & 0.073 \\
\hline & 2009 vs 2016 & -8.583 & -12.25 to -4.918 & 0.010 \\
\hline & 2009 vs 2017 & -10.5 & -16.92 to -4.082 & 0.019 \\
\hline & 2009 vs 2018 & -44.42 & -56.92 to -31.92 & 0.004 \\
\hline & 2009 vs 2019 & -45.57 & -60.45 to -30.69 & 0.006 \\
\hline \multirow[t]{10}{*}{ Kanser } & 2009 vs 2010 & 2.417 & -11.84 to 18.15 & 0.702 \\
\hline & 2009 vs 2011 & 3.75 & -9.120 to 16.62 & 0.402 \\
\hline & 2009 vs 2012 & 3.833 & -9.556 to 17.22 & 0.411 \\
\hline & 2009 vs 2013 & -1.083 & -14.64 to 12.47 & 0.961 \\
\hline & 2009 vs 2014 & -14.6 & -30.69 to 1.489 & 0.060 \\
\hline & 2009 vs 2015 & -20.1 & -31.2 to 11.1 & 0.074 \\
\hline & 2009 vs 2016 & -32.4 & -45.9 to 13.5 & 0.185 \\
\hline & 2009 vs 2017 & 6.5 & 8.014 to 21.01 & 0.023 \\
\hline & 2009 vs 2018 & 6.667 & 0.4036 to 12.93 & 0.044 \\
\hline & 2009 vs 2019 & 6.167 & 0.5299 to 11.80 & 0.042 \\
\hline \multirow[t]{10}{*}{ Tumor } & 2009 vs 2010 & -5 & -23.66 to 13.66 & 0.447 \\
\hline & 2009 vs 2011 & -18.91 & -30.9 to 11.99 & 0.520 \\
\hline & 2009 vs 2012 & -19.2 & -28.4 to 9.2 & 0.483 \\
\hline & 2009 vs 2013 & -11.62 & -25.7 to 14.08 & 0.107 \\
\hline & 2009 vs 2014 & -12.78 & -42.7 to 29.92 & 0.119 \\
\hline & 2009 vs 2015 & -22.19 & -35 to 12.81 & 0.280 \\
\hline & 2009 vs 2016 & -59.17 & -101.1 to -17.28 & 0.026 \\
\hline & 2009 vs 2017 & -60.83 & -100.8 to -20.90 & 0.022 \\
\hline & 2009 vs 2018 & -44.42 & -56.92 to -31.92 & 0.004 \\
\hline & 2009 vs 2019 & -45.57 & -60.45 to -30.69 & 0.006 \\
\hline \multirow[t]{10}{*}{ Bukol } & 2009 vs 2010 & 4.833 & -0.5178 to 10.18 & 0.061 \\
\hline & 2009 vs 2011 & 3.25 & -2.765 to 9.265 & 0.155 \\
\hline & 2009 vs 2012 & 3.583 & -4.684 to 11.85 & 0.224 \\
\hline & 2009 vs 2013 & 2.267 & -6.075 to 10.61 & 0.439 \\
\hline & 2009 vs 2014 & 1.25 & -5.24 to 6.49 & 0.295 \\
\hline & 2009 vs 2015 & 0.94 & -4.79 to 5.73 & 0.529 \\
\hline & 2009 vs 2016 & -43.43 & -88.87 to 2.034 & 0.065 \\
\hline & 2009 vs 2017 & -43.67 & -61.16 to -26.17 & 0.008 \\
\hline & 2009 vs 2018 & -44.42 & -56.92 to -31.92 & 0.004 \\
\hline & 2009 vs 2019 & -45.57 & -60.45 to -30.69 & 0.006 \\
\hline
\end{tabular}

Table 1 Comparison of cancer-related search terms from 2009 to 2019 in the Philippines. 
cancer-related search activity in the Philippines in recent years. There are several possible reasons behind this finding. First, this may likely indicate an increased interest in the disease in question, similar to a trend analysis by Dalanon and Matsuka which correlated increased dental health-related search activity with increased overall interest on the subject matter [9].

Second, increased health-related search activity may point to a move away from the previous unilateral, paternalistic, physician-centric model of healthcare towards a more empowered patient population actively participating in and engaging their own health. Increasingly, patients desire to learn more about their health and disease/s on their own rather than simply relying on healthcare professionals as the sole source of information [18, 19].

Third, an increase in search activity for a particular disease may parallel an increase in its incidence. Indeed, in the Philippines, there has been an overall increase in the incidence of all cancers in the last two decades; increased screening measures and earlier detection rates are posited to be a key driver [20].

As more and more Filipinos turn to the internet for their cancer-related queries, so do healthcare professionals increasingly need to meet them in this cyber terrain. Notably, there appears to be an increased recognition of the ever-increasing role and significance of the internet in Philippine cancer care. For example, the Philippine Society of Medical Oncology, the country's professional organization of board-certified medical oncologists, has been actively using its website to disseminate laymanized information on the symptoms, diagnostics, and treatment options for the most common cancers in the country. Similarly, more and more oncologists are using the internet for purposes of patient education and health information dissemination.

This study has several important limitations. First, demographic data such as age and sex not otherwise obtainable via Google Trends ${ }^{\text {TM }}$ would have provided a richer and deeper profile behind the internet users making these cancer-related search queries. Second, although Google is the predominant search engine locally and worldwide, there are other, non-search engine platforms, including social media, from which internet users can obtain health information. Third, this study only focused on general cancer-related search terms; future research that may seek to build upon this study may focus on specific cancer types and search queries pertinent thereto.

\section{CONCLUSION}

Analyzing the trends of internet search queries can provide rapid, unrestricted, and valuable insight on healthseeking behaviors hitherto unimaginable. This study revealed a statistically significant increase in cancerrelated search activity in the Philippines in recent years. This is a reality which must be recognized by healthcare professionals engaged in Philippine cancer care, and an opportunity which must be maximized by public health practitioners seeking novel and more targeted means of health education and information dissemination.

\section{COMPETING INTERESTS}

The author has no competing interests to declare.

\section{AUTHOR AFFILIATION}

Jose Ma. H. Zaldarriaga, MD MBA (D) orcid.org/0000-0003-36316317

Ateneo School of Medicine and Public Health, PH

\section{REFERENCES}

1. Cooper C, Mallon K, Leadbetter S, et al. Cancer Internet Search Activity on a Major Search Engine, United States 2001-2003. JMIR. 2005; 7(3): e36. DOI: https://doi.org/10.2196/jmir.7.3.e36

2. Jadad A, Sigouin C, Cocking L, et al. Internet use among physicians, nurses, and their patients. JAMA. 2002; 286(12): 1451-1452. DOI: https://doi.org/10.1001/jama.286.12.1451

3. Eysenbach $\mathbf{G}$. The Impact of the Internet on Cancer Outcomes. CA Cancer J Clin. 2003; 53: 356-371. Available at: https://acsjournals.onlinelibrary.wiley.com/doi/pdf/10.3322/ canjclin.53.6.356 accessed 26 November 2020. DOI: https:// doi.org/10.3322/canjclin.53.6.356

4. Ziebland S, Chapple A, Dumelow C, et al. How the internet affects patients' experience of cancer: a qualitative study. BMJ. 2004; 328(7439): 564. DOI: https://doi.org/10.1136/ bmj.328.7439.564

5. Peterson M, Fretz P. Patient Use of the Internet for Information in a Lung Cancer Clinic. CHEST. 2003; 123: 452-457. Available at: https://pdfs.semanticscholar. org/33ec/4edb25beb1e1ffe876d5f5d9252f4fa63246.pdf accessed 24 November 2020. DOI: https://doi.org/10.1378/ chest.123.2.452

6. Wong C, Harrison C, Britt $\mathbf{H}$, Henderson J. Patient use of the internet for health information. Aust Fam Physician. 2014; 43(12): 875-977. PMID: 25705739.

7. Potts H, Wyatt J. Survey of doctors' experience of patients using the Internet. J Med Internet Res. 2002; 4(1): 42-53. DOI: https://doi.org/10.2196/jmir.4.1.e5

8. Murray E, Lo B, Pollack L, et al. The Impact of Health Information on the Internet on the Physician-Patient Relationship. Arch Intern Med. 2003; 163(14): 1727-1734. DOI: https://doi.org/10.1001/archinte.163.14.1727

9. Dalanon J, Matsuka Y. A 10-Year Analysis of Internet Search Trends of the Oral Health-Seeking Behavior of Filipinos. PPP. 2020; 12(2): 280-284. DOI: https://doi.org/10.1002/pop4.280 
10.Nuti S, Wayda B, Ranansingje I. The Use of Google Trends in Health Care Research: A Systematic Review. PLOS ONE. 2014; 9(10): e109583. DOI: https://doi.org/10.1371/journal. pone.0109583

11.Carneiro H, Mylonakis E. Google Trends: A Web-Based Tool for Real-Time Surveillance of Disease Outbreaks. Clin. Infect. Dis. 2009; 49(10): 1557-1564. DOI: https://doi. org/10.1086/630200

12.Cervellin G, Comelli I, Lippi G. Is Google Trends a reliable tool for digital epidemiology? Insights from different clinical settings. JEGH. 7(3): 185-189. DOI: https://doi.org/10.1016/j. jegh.2017.06.001

13.Eysenbach G. Infodemiology and infoveillance: framework for an emerging set of public health informatics methods to analyze search, communication and publication behavior on the Internet. J Med Internet Res. 2009; 11(1). DOI: https:// doi.org/10.2196/jmir.1157

14.Republic of the Philippines Commission on Population. (2020). 2015 Census of Population. Available at: https://web. archive.org/web/20190403061418/http://www.popcom.gov. ph/. Accessed 8 Dec 2020.
15.Omorog C. Internet Security Awareness of Filipinos: A Survey Paper. International Journal of Computing Sciences Research. 2020; 1(4): 14-26. DOI: https://doi.org/10.25147/ ijcsr.2017.001.1.18

16.Ngelangel C, Wang E. Cancer and the Philippine Cancer Control Program. JJCO. 2002; 32(1): 52-61. DOI: https://doi. org/10.1093/jjco/hye126

17.Ludovice Z, Faraon A, Andaya J, et al. Philippine Health Statistics. Available at: doh.gov.ph. Accessed 8 Dec 2020.

18.Leydon G, Boulton M, Moynihan C, et al. Cancer patients' information needs and information seeking behavior: in depth interview study. BMJ. 2000; 320(7239): 909-913. DOI: https://doi.org/10.1136/bmj.320.7239.909

19.Jenkins V, Fallowfield L, Saul J. Information needs of patients with cancer: results from a large study in the UK cancer centres. Br J Cancer. 2002; 84(1): 48-51. DOI: https:// doi.org/10.1054/bjoc.2000.1573

20.Laudico A, Mirasol-Lumague M, Mapua C, et al. Cancer Incidence and Survival in Metro Manila and Rizal Province, Philippines. JJCO. 2010; 40(7). DOI: https://doi.org/10.1093/ jjco/hyq034

TO CITE THIS ARTICLE:

Zaldarriaga JMaH. A Ten-Year Trend Analysis of Cancer-Related Search Queries in the Philippines. International Journal of Digital Health. 2021; 1(1): 17, 1-5. DOI: https://doi.org/10.29337/ijdh.41

Submitted: 01 October 2021 Accepted: 04 November 2021 Published: 15 November 2021

COPYRIGHT:

(c) 2021 The Author(s). This is an open-access article distributed under the terms of the Creative Commons Attribution-NonCommercial 4.0 International License (CC-BY-NC 4.0), which permits unrestricted distribution, reproduction and adaptation in any medium, provided the original author and source are credited, and that the material is not used for commercial purposes.

See https://creativecommons.org/licenses/by-nc/4.0/.

International Journal of Digital Health is a peer-reviewed open access journal published by IJS Publishing Group. 